\title{
TINJAUAN EFISIENSI OPERASIONAL ALAT TANGKAP KAPAL PURSE SEINE 30 GT
}

\author{
H. C. Ririmasse ${ }^{1, *}$ \\ ${ }_{1}^{1}$ Jurusan Teknik Perkapalan Fakultas Teknik Universitas Pattimura, Ambon 97234 \\ *hedy.ririmasse@fatek.unpatti.ac.id
}

\begin{abstract}
Abstrak Penggunaan kecepatan yang berlebihan pada saat hauling akan menyebabkan inefisiensi biaya operasi. Deskripsi di atas menunjukkan bahwa perlu adanya penelitian tentang pengaruh kecepatan maksimum, penggunaan line hauler, power blok, panjang jaring, berat jaring dan kecepatan tenggelam jaring terhadap efisiensi operasi penangkapan ikan di perairan Maluku. Dengan penerapan efisiensi daya mesin, penggunaan daya mesin masih bisa dioptimalkan untuk memutar roller dan line hauler sebagai alat bantu penangkapan.

Hasil perhitungan efisiensi daya mesin diperoleh sekitar 75,08\%, sedangkan efisiensi waktu operasi sekitar 55,15\%, efisiensi palka sekitar 35,2 \%, dan efisiensi alat tangkap sekitar $72,67 \%$. Dengan mengoptimalkan daya mesin untuk memutar line hauler dan roller mampu memberikan tambahan pendapatan ABK.
\end{abstract}

Kata kunci: Purse seine, Roller, Line hauler, Efisiensi.

\begin{abstract}
The use of abundant speed at the hauling time will cause the inefficiency operating expenses. This indicating that need of research about maximum speed influence, use of line hauler, power block, long of net, weight of net and rate sink the net with the efficiency operate for the fish catch in water territorial of Moluccas. With the applying of efficiency of machine energy, the use of machine energy still optimal to turn around the roller and line hauler as a catch's auxiliary equipment. The result of this research shows that efficiency of machine power about 75,08\%, efficiency of time operation about 55\%, efficiency of fish hold about $35,2 \%$ and efficiency of purse seine capture equipment about 72,67 \%. The Use of this auxiliary equipment will save the amount of man power of crew vessel from twenty eight to ten, so that crew vessel's earnings can be rise.
\end{abstract}

Keywords: Purse seine, roller, line hauler, efficiency.

\section{PENDAHULUAN}

Peningkatan atau penambahan kecepatan kapal untuk menangkap ikan yang lebih banyak dengan menambah daya dan jumlah mesin kapal dilakukan para nelayan. Penambahan daya dan jumlah mesin kapal tanpa disadari telah membuat biaya operasi (operation cost) semakin membengkak sedangkan sumberdaya ikan semakin terbatas. Kondisi ini menyebabkan persaingan yang semakin ketat antar nelayan.

Kondisi ini berakibat pada meningkatnya tingkat persaingan usaha perikanan tangkap dan konflik nelayan [1]. Keterbatasan sumberdaya perikanan disebabkan oleh pola tangkap nelayan yang tidak memperhatikan kelestarian sumberdaya perikanan dan lingkungan [2].

Menurut Diniah dkk [3], untuk mengatasi keterbatasan sumberdaya perikanan dan peningkatan biaya operasi penangkapan maka nelayan harus menjaga kelestarian lingkungan dan melakukan efisiensi biaya operasi penangkapan dengan memperbaiki terknologi penangkapan yang lebih efisien dan ramah lingkungan.

Alat tangkap purse seine merupakan alat tangkap yang cukup produktif dan tergolong alat tangkap aktif [4]. Keterbatasan sumberdaya ikan dan meningkatnya biaya operasi penangkapan merupakan dilema yang harus dihadapi dengan melakukan efisiensi dan efektifitas operasi 
penangkapan [5]. Referensi [6] menyatakan bahwa hasil tangkapan ikan akan meningkat dengan meningkatnya kecepatan kapal saat operasi penangkapan, namun sampai pada kecepatan tertentu hasil tangkapan akan konstan. Hal ini menunjukkan bahwa kecepatan kapal sudah mencapai titik maksimum dan penggunaan kecepatan yang berlebihan akan menyebabkan inefisiensi biaya operasi.

Tujuan operasi penangkapan adalah untuk memperoleh jumlah tangkapan yang sebanyakbanyaknya dan ramah lingkungan. Ada tiga faktor yang harus dikendalikan untuk mencapai tujuan efisiensi operasi penangkapan yaitu ikan, kapal, dan alat tangkap.

Pengendalian gerakan ikan saat operasi penangkapan dilakukan dengan dua cara yaitu dengan alat yang mampu memonitor gerakan ikan dan lampu. Alat pemonitor gerakan ikan digunakan untuk mengetahui besarnya gerombolan dan jenis ikan yang menjadi sasaran penangkapan. Alat pemonitor ikan terdiri dari fish finder, sonar, dan kamera bawah laut [4].

Operasi penangkapan ikan dengan menggunakan lampu (light fishing) banyak digunakan oleh nelayan jawa, karena alat ini sangat murah dan mudah dioperasikan. Ikan sangat tertarik terhadap cahaya lampu karena mata ikan selalu menyesuaikan dengan intensitas cahaya yang ada di sekitarnya. Referensi [7], ikan memberikan reaksi positif terhadap cahaya dengan intensitas antara 0,01 0,001 lux dan sensitifitas mata ikan laut tergolong sangat tinggi yaitu sekitar $75 \%$ untuk cahaya warna biru-hijau. Alasan di atas yang mendorong para nelayan menggunakan lampu sebagai alat bantu (auxiliary equipment) operasi penangkapan.

Biaya operasional penangkapan sangat dipengaruhi oleh faktor bahan bakar, konsumsi $\mathrm{ABK}$, alat bantu penangkapan, dan pendingin ikan. Referensi [5] menyatakan, biaya bahan bakar untuk kapal purse seine mencapai $60 \%$ dari total biaya operasi penangkapan. Tingginya biaya bahan bakan disebabkan kapasitas mesin terpasang terlalu besar sehingga konsumsi bahan bakar tinggi dan penggunaan daya kurang efisien. Kapal ikan yang mempunyai ukuran panjang kurang dari 35 meter umumnya terjadi kebutuhan power yang sangat signifikan untuk kecepatan di atas 7 knot.

Efisiensi biaya operasi dilakukan dengan menurunkan kebutuhan daya mesin sesuai dengan kecepatan maksimum operasi penangkapan dan pemanfaatan sisa daya mesin untuk menggerakkan alat bantu penangkapan (auxiliary equipment). Pola operasi yang sesuai dengan karakteristik perairan dan kemampuan nakoda memprediksi gerakan ikan akan menentukan keberhasilan operasi penangkapan.

Bentuk rancangan dan dimensi alat tangkap purse seine harus sesuai dengan bentuk kapal, alat bantu penangkapan, pola operasi dan jenis ikan. Untuk ikan perenang cepat dan pola operasinya dilakukan pada siang hari mempunyai ukuran yang lebih panjang dari pada purse seine yang pola operasinya malam hari. Jaring purse seine yang baik mempunyai kecepatan tenggelam yang tinggi, sehingga jumlah ikan yang meloloskan diri sangat kecil. Ref. [8], jaring purse seine yang baik mempunyai gaya extra bouyancy sekitar $25-35 \%$.

Tujuan dari penelitian ini adalah menghitung efisiensi dan meningkatkan efektifitas operasi penangkapan ikan para nelayan menggunakan purse seine.

Penelitian ini memberikan gambaran tentang faktor-faktor yang mempengaruhi efisiensi operasi penangkapan khususnya daya mesin, waktu operasi dan tenaga $\mathrm{ABK}$ yang digunakan.

\section{BAHAN DAN METODE}

Metode yang digunakan untuk menganalisis efisiensi operasi penangkapan adalah dengan menggunakan analisis regresi. Metode regresi digunakan untuk mengetahui sejauh mana pengaruh faktor-faktor tersebut terhadap efisiensi dan berapa besarnya. Efisiensi operasi penangkapan ikan sangat dipengaruhi oleh harga bahan bakar, konsumsi $\mathrm{ABK}$, pola penangkapan, jumlah $\mathrm{ABK}$ dan efektifitas operasi [5].

\subsection{Data}

Data primer yang diambil antara lain: data dimensi kapal dan mesin, data alat tangkap purse seine, data kecepatan dan waktu yang dibutuhkan kapal saat operasi penangkapan, hasil tangkapan ikan tiap setting, dan biaya operasi penangkapan tiap trip. Data primer digunakan untuk menganalisis efisiensi operasi penangkapan dengan alat tangkap purse seine dan mencari alternatif pola operasi penangkapan yang lebih efisien.

Data sekunder digunakan untuk memprediksi potensi perikanan, perkembangan teknologi perikanan (alat tangkap dan kapal).

Analisis data dilakukan dengan dua tahapan yaitu analisis regresi dan analisis efisiensi. Analisis regresi bertujuan untuk mengetahui besarnya pengaruh kecepatan kapal terhadap hasil tangkapan ikan, 
sedangkan analisis efisiensi bertujuan untuk mengetahui efisiensi daya mesin, efisiensi waktu operasi, efisiensi palka dan efisiensi alat tangkap. Hasil dari analisis tersebut dapat dijadikan dasar untuk mencari pola operasi penangkapan yang lebih efisien.

\subsection{Analisis Regresi}

Analisis regresi berusaha menemukan suatu garis linier yang paling mewakili titik-titik pada grafik. Untuk menemukan menemukan garis linier semacam ini harus menggunakan metode kuadrat terkecil atau least square. Persamaan regresi sederhana seperti berikut ini:

$$
Y=a+b \cdot X+e
$$

Dimana :

$Y:$ Nilai $Y$ prediksi

$a$ : Intersep atau nilai rata-rata $\mathrm{Y}$ prediksi jika $\mathrm{X}=0$

$b$ : Slope atau rata-rata perubahan pada $\mathrm{Y}$ jika $\mathrm{X}$ berubah satu satuan.

$e$ : Kesalahan prediksi (Error)

$X$ : Variabel bebas

Analisa regresi pada penelitian ini untuk menentukan besarnya pengaruh kecepatan terhadap hasil tangkapan ikan, dimana kecepatan sebagai faktor penentu dan hasil tangkapan sebagai faktor yang ditentukan.

\subsection{Menghitung Efisiensi Alat Tangkap}

Efisiensi Alat tangkap diperoleh dengan membandingkan luas jaring saat operasi penangkapan dengan luas jaring saat bukaan mata jaring maksimum. Nilai efisiensi alat tangkap yang tinggi mencerminkan luasan jaring yang maksimum saat operasi penangkapan, sehingga diharapkan hasil tangkapan maksimum pula. Rumus efisiensi alat tangkap purse seine adalah:

$$
\eta=\frac{A}{A_{0}} x 100 \%
$$

\section{HASIL DAN PEMBAHASAN}

\subsection{Efisiensi Daya Mesin.}

Efisiensi daya mesin diperoleh dengan membandingkan kebutuhan daya saat kecepatan maksimum penangkapan dengan daya terpasang pada kapal.

\subsection{Analisis Regresi Kecepatan terhadap Hasil Tangkapan Ikan.}

Berdasarkan analisis regresi, kecepatan kapal dan kebutuhan bahan bakar berpengaruh nyata terhadap hasil tangkapan ikan sebesar $63 \%$ dari total faktor yang ada. Pengaruh kecepatan kapal terhadap hasil tangkapan ikan menjadi titik tekan dari efisiensi, sehingga perlu dicari kecepatan maksimum penangkapan.

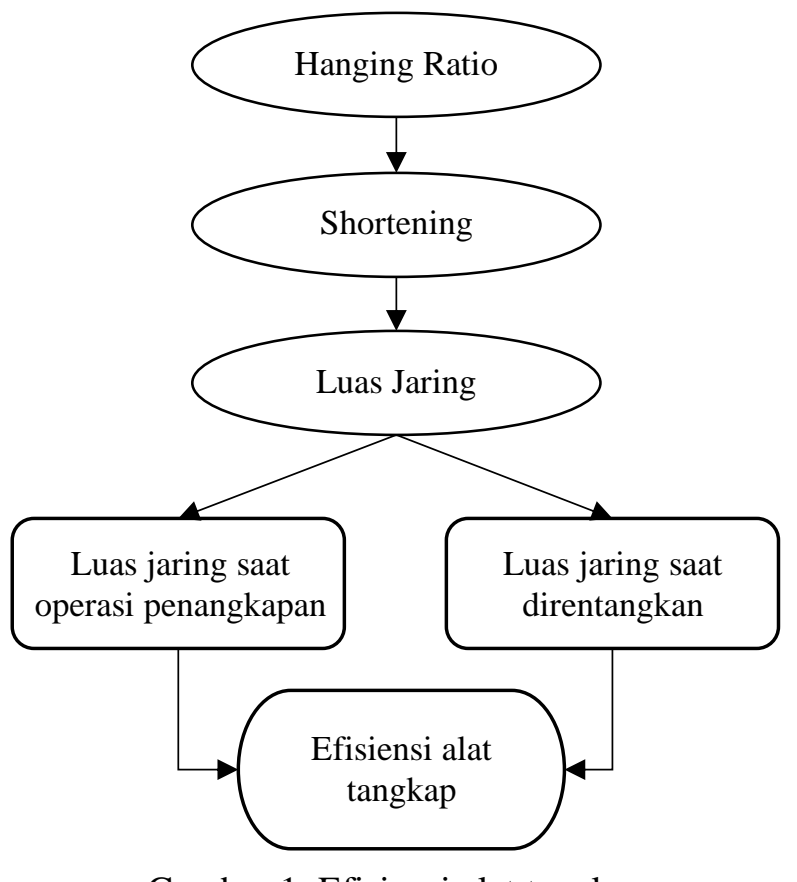

Gambar 1. Efisiensi alat tangkap

\subsection{Penghitungan Kecepatan Maksimum Penangkapan.}

Penentuan titik kecepatan maksimum ditentukan berdasarkan hasil tangkap yang paling tinggi dengan kecepatan dan waktu yang paling kecil. Penentuan titik kecepatan maksimum diperoleh dengan meningkatkan kecepatan kapal sampai titik tertentu dimana hasil tangkapan mencapai titik konstan. Kecepatan kapal dimulai dari 6,85 knot sampai 8,25 knot ini didasarkan pada Ayodhya [9], yang mengatakan bahwa kecepatan renang ikan pelagis kecil seperti layang, kembung dan lemuru sekitar 5 knot. Berdasarkan hasil pengamatan, kecepatan kapal di bawah 6,5 knot kurang efektif untuk menangkap ikan karena banyak ikan yang lolos dan beberapa kali mengalami kegagalan operasi penangkapan. Berdasarkan hasil analisa diperoleh bahwa kecepatan maksimum penangkapan diperoleh saat kecepatan 8,01 knot dengan hasil tangkapan ikan sekitar 211,5 kg. Kecepatan operasi penangkapan di atas 8,01 knot sudah tidak efisien lagi karena terjadi lonjakan konsumsi bahan bakar 
yang yang cukup signifikan dan hasil tangkapan tidak seimbang dengan biaya operasi.

\subsection{Proyeksi Perkembangan Alat Tangkap Purse Seine}

Alat tangkap purse seine tergolong alat tangkap yang sangat produktif dibandingkan dengan pancing, gillnet dan payang, namun biaya operasinya juga sangat tinggi. Tingginya biaya operasi penangkapan disebabkan oleh harga bahan bakar yang mahal dan penggunaan tenaga ABK yang banyak.

Alat tangkap purse seine masih sangat memungkinkan berkembang pesat. Ada beberapa alasan mengapa alat tangkap purse seine masih berpotensi diantaranya:

Alat tangkap purse seine tergolong alat tangkap aktif mengejar gerombolan ikan sehingga mempunyai nilai produktifitas yang sangat tinggi dibandingkan dengan pancing, gillnet dan payang.

Efisiensi operasi penangkapan dengan multi alat tangkap dan penggunaan alat bantu penangkapan (auxiliary equipment) masih terbuka lebar untuk dilakukan.

\subsection{Pengaruh Efisiensi Daya Mesin terhadap Waktu Operasi}

Berdasarkan analisa efisiensi daya mesin dan waktu operasi, penggunaan line hauler dan roller mampu menghemat waktu operasi penangkapan sekitar 55,15\%.

\subsection{Pengaruh Efisiensi Daya Mesin terhadap Tenaga ABK}

Tenaga ABK yang dibutuhkan dalam operasi penangkapan sekitar 28 orang mampu menghemat tenaga ABK sekitar 18 orang, dan kapal mampu melakukan operasi penangkapan dengan 10 orang saja, yaitu 1 orang nakoda kapal, 1 orang pencari dan pemantau ikan, 2 orang menata tali kolor dan 6 orang menarik jaring sedangkan Roller berfungsi untuk mengangkat jaring ke atas kapal.

\subsection{Pengaruh Efisiensi Daya Mesin dan Waktu Operasi terhadap Hasil Tangkapan}

Kapal purse seine setiap trip mampu melakukan operasi penangkapan antara 3-5 kali, satu kali dilakukan pada sore hari tanpa menggunakan lampu dan 4 kali pada malam hari dengan bantuan lampu. Waktu yang dibutuhkan untuk melakukan satu kali operasi penangkapan sekitar 64,37 menit dengan menggunakan alat bantu line hauler sebagai penarik tali kolor.

Sedangkan dengan menggunakan line hauler dan roller, waktu yang dibutuhkan untuk melakukan satu kali operasi penangkapan sekitar 35,50 menit, sehingga mampu menghemat waktu operasi sekitar 28,8 menit atau sekitar $45 \%$ dari total waktu operasi penangkapan.

\subsection{Pengaruh Efisiensi Daya Mesin terhadap Jumlah Setting dan Hasil Tangkapan.}

Penggunaan line hauler dan roller mengakibatkan jumlah setting meningkat dari 5 kali setting dalam tiap trip meningkat menjadi 7 kali setting tiap trip. Meningkatnya jumlah setting mampu meningkatkan hasil tangkapan ikan dari $879,8 \mathrm{~kg}$ tiap trip menjadi $1.286 \mathrm{~kg}$ tiap trip.

\subsection{Perbaikan Pola Penangkapan Purse Seine}

Keberadaan line hauler dan roller mampu menghemat waktu operasi penangkapan dan tenaga ABK berkurang. Jumlah ABK di atas ditentukan berdasarkan tugas dan fungsi masing-masing yaitu 1 orang nakoda kapal, 2 orang menata tali kolor, 6 orang menarik dan menata jaring dan 1 orang pemberi komando.

a. Pola penangkapan yang ada sekarang.

Alat bantu penangkapan:

$>$ Line hauler untuk menarik tali kolor bawah.

$>$ Lampu sebagai pengumpul ikan.

b. Pola penangkapan hasil kajian

Alat bantu penangkapan:

$>$ Line hauler untuk menarik tali kolor bawah dan tali kolor atas.

$>$ Roller untuk mengangkat jaring ke atas kapal.

$>$ Lampu sebagai pengumpul ikan.

Kajian pola penangkapan di atas didasarkan kepada hasil analisa efisiensi daya mesin, waktu operasi dan alat tangkap, sehingga untuk penerapannya harus mempertimbangkan faktor kemampuan dan kebiasaan nelayan.

\section{KESIMPULAN}

Efisiensi operasi penangkapan merupakan suatu langkah yang bertujuan untuk mengurangi biaya operasi penangkapan dengan mengoptimalkan proses penangkapan dan alat bantu penangkapan. Berdasarkan hasil penelitian kali ini dapat ditarik suatu kesimpulan sebagai berikut: 
1. Kecepatan kapal sangat berpengaruh terhadap hasil tangkapan ikan yaitu sebesar $63 \%$ dari total faktor yang ada, dan kecepatan maksimum dicapai pada kecepatan 8,01 knot dengan hasil tangkapan sekitar $211,5 \mathrm{~kg}$.

2. Hasil perhitungan efisiensi daya mesin diperoleh sekitar 75,08\%, sedangkan efisiensi waktu operasi sekitar $55,15 \%$, efisiensi palka sekitar 35,2\%, dan efisiensi alat tangkap sekitar $72,67 \%$.

\section{UCAPAN TERIMA KASIH}

Penelitian ini terlaksana atas bantuan Dana Penelitian yang berasal dari PNBP Fakultas Teknik tahun 2019. Untuk itu, penulis menyampaikan terima kasih kepada Pimpinan Fakultas Teknik Universitas Pattimura.

\section{DAFTAR PUSTAKA}

[1] I. Triarso, "Potensi dan Peluang Pengembangan Usaha Perikanan Tangkap Di Pantura Jawa Tengah," Saintek Perikan. Indones. J. Fish. Sci. Technol., vol. 8, no. 1, pp. 65-73, Aug. 2012, doi: 10.14710/ijfst.8.1.6573.

[2] E. Wicaksono and Y. Effendi, "Determinan Efisiensi Nelayan di Indonesia: Sebuah Analisis Stochastic Frontier," J. Sos. Ekon. Kelaut. Dan Perikan., vol. 14, no. 1, pp. 115124, Jun. 2019, doi: 10.15578/jsekp.v14i1.6868.

[3] Diniah, Pemanfaatan Sumberdaya Perikanan Tuna-Cakalang Secara Terpadu. Bogor: IPB.

[4] G. Guntur, F. Fuad, and A. R. Faqih, "Gaya Extra Bouyancy dan Bukaan Mata Jaring sebagai Indikator Efektifitas dan Selektifitas Alat Tangkap Purse Seine di Perairan Sampang Madura," J. Kelaut. Indones. J. Mar. Sci. Technol., vol. 6, no. 2, pp. 157-161, 2013, doi: 10.21107/jk.v6i2.790.

[5] M. Muhammad, "Analisis efisiensi dan efektifitas operasi kapal purse seine di Pelabuhan Perikanan Nusantara Ternate Provinsi Maluku Utara," Agrikan J. Agribisnis Perikan., vol. 10, no. 1, pp. 8-21, May 2017, doi: 10.29239/j.agrikan.10.1.8-21.

[6] A. Muntaha, S. Soemarno, S. Muhammad, and S. Wahyudi, "Kajian kecepatan kapal purse seiner terhadap hasil tangkapan ikan di perairan Probolinggo," J. Kelaut. Indones. J. Mar. Sci. Technol., vol. 6, no. 1, pp. 29-35, Apr. 2013, doi: 10.21107/jk.v6i1.830.
[7] T. Laevastu and M. L. Hayes, Fisheries Oceanography and Ecology. Fishing News Books Ltd, 1982.

[8] A. L. Friedman, Perhitungan Dalam Merancang Alat Penangkap Ikan. Semarang: Penangkapan Ikan, 2009.

[9] A. U. Ayodhya, Metode Penangkapan Ikan. Bogor: Yayasan Dewi Sri, 1981. 